\title{
1 Experiência e Espetacularização como Chaves para Pensar a Cultura e a Arte na Contemporaneidade*
}

\author{
Experience and Spectacularization as Keys to thinking Culture and Art in \\ Contemporaneity
}

Lúcia Maciel Barbosa de Oliveira**

*Recebido em: 08.03.2017. Aprovado em: 30.08.22017. Uma versão revista e ampliada do presente artigo será publicada em Revista de Estudos Avançados IEA - USP em 2018

** Docente e pesquisadora no Departamento de Biblioteconomia e Documentação da ECA/USP. Email: mbol.lucia@gmail.com
Resumo: Autores como Arendt e Agambem mostram como a arte é um campo privilegiado e como as obras de arte constituem objetos culturais por excelência. Isso leva à questão: há disposição para a arte hoje, para sua fruição, sua prática? As artes tornaram-se fenômeno de massa nas instituições que tradicionalmente as acolheram, aparentemente mais consumidas do que apropriadas. As narrativas que definiam as formas de representar o mundo, negando, excluindo e espetacularizando as diferenças a partir de perspectivas demarcadas ganharam novo contornos que forçaram as fronteiras da representação, instituindo novos assuntos, novos atores, novas abordagens, outros olhares e sensibilidades. Isto leva à discussão da cultura comum não como cultura homogeneizadora, mas como a que se constrói a partir do compartilhamento, das tensões e contradições, das interações e da participação, da criatividade coletiva, da afirmação de potências, das visibilidades, dos aparecimentos e dos afetos.

Palavras-Chave: Arte; Cultura; Espetáculo; Narrativa.
Abstract: starting with authors like Arendt and Agambem, art shows are a privileged field and how works of art constitute cultural objects par excellence. Which leads to the question: is there a disposition for art today, for its enjoyment, its practice? The arts became a mass phenomenon in the institutions that traditionally welcomed them, apparently more consumed than appropriate. The narratives that defined the ways of representing the world, denying, excluding and spectacularising the differences from demarcated perspectives, gained new contours that forced the boundaries of representation, instituting new subjects, new actors, new approaches, other glances and sensibilities. This leads to the discussion of common culture not as a homogenizing culture, but as that which is constructed from sharing, tensions and contradictions, interactions and participation, collective creativity, affirmation of potencies, visibilities, appearances and of affections.

Keywords: Art; Culture; Show; Narrative. 


\section{Introdução}

No momento em que fui convidada a escrever o presente artigo, estava tomada pela leitura do diário de filmagem de Fitzcarraldo, de Werner Herzog, intitulado Conquista de lo inútil, nome mais do que apropriado para a saga que é representada no filme e narrada no diário que registra os dois longos anos necessários à produção e à filmagem em condições extremas. A obsessão que marca a figura de Fitzcarraldo, personagem central do filme interpretado por Klaus Kinski, é característica também de Herzog, que se lança à aventura limite que é a filmagem da obra na selva amazônica, permanentemente colocando obstáculos à continuidade do filme, naquilo que poderíamos interpretar como uma luta extrema entre a natureza e a cultura.

Para os que não conhecem o filme, uma pequena sinopse: Fitzcarraldo é um amante da ópera que tem a obsessão de construir um teatro no meio da floresta, na Amazônia Peruana, para levar Caruso a encenar uma obra. Para conseguir realizar seu plano, precisa antes ganhar dinheiro com a extração da borracha, produto vendido a preços altos no mercado internacional, no apogeu do ciclo da borracha no final do século XIX, em terras remotas que conseguiu autorização para explorar. Com a ajuda dos índios, Fitzcarraldo precisa transportar um enorme navio a vapor pelo rio; em seguida, transpor uma pequena montanha a fim de alcançar outro rio, desafiado pela exuberância da selva, sempre a espreitar. Fitzcarraldo é baseado na figura de Brian Sweeney Fitzgerald (Fitzcarraldo, como era chamado pelos nativos), que já havia investido em projetos mirabolantes, como a estrada de ferro Transandina e uma fábrica de gelo, o que lhe rendeu o apelido de
“ conquistador do inútil” . A viagem evidencia o processo de acirramento da obsessão, na transposição de morros e matas, no sofrimento e perda de vidas humanas para a conquista do nada (ou para uma grande conquista?).

A obra monumental filmada por Herzog tem seu duplo na produção do filme, narrada por ele no diário ao longo de mais de dois anos, de junho de 1979 a novembro de 1981, no qual vão sendo registradas impressões e dificuldades para levar sua obsessão adiante, frente aos desafios mais extremos, de mortes e perdas materiais à solidão e ao mergulho em um mundo que the é estranho e que procura dominar: "la vida está mortalmente encendida o mortalmente apagada”, registra (HERZOG, 2013, p.70). Há um momento em que Herzog anota no diário que pensava ele mesmo interpretar Fitzcarraldo, quando sua obsessão ganhava novos contornos frente às dificuldades impostas pela produção de um filme de tal envergadura na selva, que se fazia presente a todo momento, reinserindo-se por vezes de maneira suave, por vezes de maneira bruta, nos espaços abertos pelos forasteiros.

A atração desafiadora da selva e da empreitada o fazia sentir deslocado fora dela, em permanente condição de estranhamento. Quando estava no Rio de Janeiro para resolver questões da produção do filme, em julho de 1980, Herzog narra o incômodo de uma conversa com uma jovem elegante que quer falar sobre arte: "yo ladré, qué arte, y algo desconcertada por mi hostilidad ella dijo: el arte en sí" (idem, p.88). Tal citação é emblemática para um dos ângulos possíveis de leitura do filme e de seu duplo (a saga de sua realização), pensando a arte como a conquista do inútil, ou melhor, a arte como ação sem 
finalidade, tal como definida por Hannah Arendt em seu texto A crise da cultura. Nele, Arendt vai refletir acerca do complexo relacionamento entre sociedade e cultura, sobretudo após o advento da cultura de massa, quando todos os estratos da população são incorporados a ela, o que significa que há poucas brechas de ação. $\mathrm{O}$ artista, "derradeiro indivíduo que restou na sociedade de massa" (ARENDT, 2013, p. 252), interessa à autora não por seu individualismo subjetivo, mas pelo fato de, como produtor de obras de arte, "objetos culturais máximos" (idem), ter se voltado contra a sociedade, em oposição à mentalidade pragmática que julga o valor das coisas por seu grau de utilidade imediata, por sua finalidade, e que, "por conseguinte, não tinha consideração alguma por objetos e ocupações inúteis tais como os implícitos na cultura e na arte" (idem, p. 253).

A monopolização da cultura por uma burguesia ascendente em busca de posição social e status foi fator decisivo para a "rebelião do artista contra seus novos protetores; eles pressentiram o perigo de serem banidos da realidade para uma esfera de tagarelice refinada, onde aquilo que faziam perderia todo o sentido" (ibidem, p. 254). Portanto, destaca Arendt, o que está em jogo é a própria cultura e sua continuidade, na medida em que o julgamento dos objetos culturais é possível a partir de sua permanência: "somente o que durará através dos séculos pode se pretender em última instância um objeto cultural" (idem, p.255). Em outras palavras, o consumo da cultura sem que haja tempo para uma apropriação efetiva acirrou-se ainda mais com o advento da sociedade de massa que não precisa de cultura, mas de diversão, rapidamente consumida como os demais produtos - entretenimento para as horas mortas não despendidas em atividades produtivas, sem que haja possibilidade de abrir brechas para "um tempo em que estejamos libertos de todos os cuidados e atividades requeridos pelo processo vital e livres, portanto, para o mundo e sua cultura" (ibidem, p.257).

A cultura, para Arendt, é o modo de relacionamento do homem com as coisas do mundo, sobretudo com respeito ao que é menos útil, como a obra de artistas, poetas, músicos, filósofos. A arte é campo privilegiado e as obras de arte constituem objetos culturais por excelência, o que significa que, para Arendt, cultura e arte não são a mesma coisa: a arte potencializa devires, é feita com o fim único do aparecimento. Há disposição para a arte hoje, para sua fruição, sua prática? Em um mundo de consumos e descartes rápidos, há espaço para o que não tem utilidade, na esteira do pensamento de Arendt, para a conquista do inútil, para falar com Herzog?

Como observara Arendt, a diversão e o entretenimento tornaram-se a tônica dominante; a cultura tornou-se também produto de consumo; assim como muitos museus e seus acervos, compostos de grandes obras, entraram para o circuito de peregrinação de turistas e visitantes que para lá acorrem. É curioso como a conquista de número expressivo de visitantes que guiou a ação de museus e espaços expositivos foi alcançada, mesmo em países como o Brasil, com sérias deficiências educacionais, o que coloca a questão da qualidade da visita, da apropriação do que é visto e não apenas consumido, como questão fundamental para as instituições. Utilizo aqui a distinção entre público e visitante operada por Teixeira Coelho em seu mais novo livro Com o cérebro na mão: 
${ }^{1}$ A arte é entendida aqui, como a esfera que possibilita que experiências significativas aconteçam a partir de objetos singulares: "uma obra de arte é um objeto que sobrevive à vida e à intenção que a gerou, e a todos os discursos produzidos sobre la" (MAMMI, 2012). tilósofo lósofo Lorenzo Mammi. Refletindo acerca do estado atual das artes visuais no Brasil e no mundo, Mammi defende a ideia de que não há mais movimentos de transformação da linguagem artística, o que deixa à arte a função de criar estranhezas. A perspectiva do estranhamento um desafio a ser vencido na relação com os públicos, já que não se trata de simples acesso, mas de apropriação subjetiva, que vai na contramão da cultura do entretenimento, que é a tônica dominante.
Esse é mesmo o conceito próprio de público em política cultural: conjunto relativamente homogêneo de pessoas que se entregam regularmente a uma determinada prática cultural. As pessoas que ocasionalmente acorrem a uma prática, por exemplo uma bienal de artes, mas que não são habituées dessa prática, são apenas os visitantes desse evento, não seu público (TEIXEIRA COELHO, 2015, p.25).

O autor destaca ainda como a ideia de entretenimento é central para o ecossistema comunicativo do século XXI. O desenvolvimento e barateamento das tecnologias de informação e comunicação (TICs), sobretudo dos dispositivos móveis como smartphones, cria uma outra relação dos sujeitos com o tempo e o espaço, desenvolvendo novas percepções, o que se constitui em desafio para as instituições culturais e para a própria cultura no século XXI. Se um dos motores da Política Cultural foi a escassez dos bens ou produtos culturais, sua produção e distribuição, como afirma Teixeira Coelho, em grande parte a tarefa foi realizada, tendo a tecnologia papel preponderante para que isso ocorresse. A partir dessas considerações, o autor questiona se o discurso corrente, centrado na carência de equipamentos culturais formais - cinemas, salas de concerto, bibliotecas etc. - em regiões desprovidas deles, como na cidade de São Paulo, ainda se sustenta, na medida em que as práticas culturais não são as mesmas, não se dão da mesma forma e apenas nos espaços tradicionais. Em suas palavras: “a recomendação de mais equipamentos culturais não seria, em alguma medida, uma questão de antiga política cultural?" (TEIXEIRA COELHO, 2015, p. 22), o que exigiria que a política cultural se alterasse ou se colocasse outras questões para estar à altura dos desafios do século XXI, ao novo ecossistema cultural.
Vivemos momentos complexos para museus e centros culturais: por um lado há excesso de visitantes que acorrem às exposições blockbusters, aos grandes museus consagrados como o Louvre, o MoMA, o Metropolitan de Nova York, a Tate Modern, ao Beaubourg, cada qual com milhões de visitantes ao ano (entre 5 e 10 milhões) que se espremem para ver as grandes obras e percorrer as galerias em marcha rápida, fotografando ou se fotografando tendo-as como pano de fundo. As artes tornaram-se fenômeno de massa nessas instituições, aparentemente mais consumidas do que apropriadas. Em São Paulo, tal fenômeno tem sido uma constante nas exposições promovidas por museus e centros culturais como o MASP, o Instituto Tomie Ohtake, o Centro Cultural Banco do Brasil, a Pinacoteca do Estado. Uma questão pertinente seria, afinal, se a afluência a esses espaços consagrados significaria uma experiência significativa para os sujeitos, potencializaria as apropriações necessárias para que tivessem significado efetivo, ou constituir-se-ia em consumo puro e simples que pouco acrescenta às existências já tão bombardeadas por imagens e informações diariamente ${ }^{1}$.

Para o filósofo Giorgio Agamben, o homem contemporâneo foi expropriado da experiência, tornando-se incapaz de fazer e transmiti-la, de elaborá-la, o que torna insuportável a existência cotidiana:

dia a dia do homem contemporâneo não contém quase nada que seja ainda traduzíve em experiência: não a leitura do jornal, tão rica em notícias do que lhe diz respeito a uma distância insuperável; não os minutos que passa, preso ao volante, em um engarrafamento; não a viagem às regiões ínferas nos vagões do metrô nem a

Dossiê Práticas e Políticas Culturais: Paradoxos e diálogos com a tecnologia

Arquivos do CMD, Volume 5, N.1. Jan/Jul 2017 
manifestação que bloqueia a rua; não a névoa dos lacrimogêneos que se dissipa lenta entre os edifícios do centro e nem mesmo os súbitos estampidos de pistola detonados não se sabe onde; não a fila diante dos guichês de uma repartição ou a visita ao país de Cocanha do supermercado nem os eternos momentos de muda promiscuidade com desconhecidos no elevador ou no ônibus. O homem moderno volta para casa à noitinha extenuado por uma mixórdia de eventos - divertidos ou maçantes, banais ou insólitos, agradáveis ou atrozes -, entretanto nenhum deles se tornou experiência (AGAMBEN, 2012, p.22)

O tempo simultaneamente extenuado e excitado em que vivemos exigem um gesto de interrupção que permita a abertura ao devir como fluxo permanente e ininterrupto que potencialize experimentações. A experiência ocorre quando podemos subjetivá-la. A visita a museus e centros culturais superlotados, em que o ritmo da visitação é dado pela multidão presente permitiria a efetuação da experiência, o tempo necessário para que a potencialidade da arte e da cultura se consubstancie, para que a vida sem finalidades abra espaço? Se o excesso e a excitação são a tônica em muitas instituições culturais, há outras que veem seu público minguar ou assistem ao declínio do seu público que não se renova (caso de renomadas instituições como a Metropolitan Opera) ou, ainda, aquelas que não são apropriadas em toda sua potencialidade pelos públicos que as veem com reticência. As instituições culturais talvez não tenham compreendido que não se pode criar cultura, praticá-la, sem os interessados. Seguem falando para si mesmas, sem compartilhar incertezas, sem compreender que a cultura atual é troca permanente, performativa, interativa, que promove a experiência do diverso, a capacidade de afetar e ser afetado, de surpreender-nos. A cultura é diálogo, pois os "sujeitos são dialógicos, não no sentido binário do diálogo entre dois sujeitos já constituídos, mas no sentido de sua relação com outro ser fundamentalmente constitutiva do sujeito" (HALL, 2009).

Para Néstor García Canclini (2013), nos novos cenários de circulação da arte e da cultura, os museus devem deixar de ser um repositório ou um arquivo de coleções para se transformarem em elemento do processo criativo, modificando sua função e sua estrutura. Museus e centros culturais estão instados a repensar-se, a reconsiderar seus vínculos com seus públicos e com as cidades, o que significa uma reflexão articulada à ideia de participação, de proximidade. Canclini questiona se os museus redesenhados como centros culturais polivalentes poderiam resgatar formas de interação criativa e uma multiculturalidade vivida mais como interação produtiva do que como ameaça. Questiona, ainda, até que ponto os museus podem contribuir para a socialização e a visibilidade de uma interpretação compartilhada da história urbana, uma reflexão e convivência fundamentada na multi e na interculturalidade. Interessa a Canclini pensar tais instituições em cenários nos quais uma multiplicidade de atores está em cena, em que novas práticas culturais estão em jogo e o desafio é a interação, as novas relações e reflexões que podem operar no interior das instituições. “¿Cómo pueden los museos y centros culturales participar en este debate sobre el sentido de la cultura en la ciudad?" (CANCLINI, 2013, p. 16).

Subjaz às indagações de Canclini a questão do patrimônio cultural como sedimentação de certezas, ou seja, de que forma o 
patrimônio é estabelecido e consolidado, ganhando uma dimensão universal, cujo significado não é socialmente compartilhado, evidenciando jogos de poder, desconhecendo a diversidade e sua pouca propensão à interculturalidade (CANCLINI, 2010). O patrimônio deveria ser abordado como espaço de disputa, material e simbólica, espaço de tensão. Acervos poderiam ser lidos na mesma chave, e os espaços que os detêm deveriam se pensar como espaços de negociação de sentidos, que assumem a tensão como força propulsora, pondo em xeque a narrativa que os organiza. Segundo Martín-Barbero (2015), a interculturalidade nomeia a impossibilidade de uma diversidade cultural compreendida de cima, significa o “entrecruzamento de radiações". Que instituições culturais estão abertas a essa dinâmica?

As narrativas que definiam as formas de representar o mundo, negando, excluindo e espetacularizando as diferenças a partir de perspectivas demarcadas, ganharam novos contornos que forçaram as fronteiras da representação, instituindo novos assuntos, novos atores, novas abordagens, outros olhares e sensibilidades. A reivindicação de maneiras alternativas de relatar, representando desejos e interesses diversos, vem abrindo brechas, evidenciando dissensos, dando visibilidade ao oculto, voz aos silenciados, eliminando mediações. Tal perspectiva cria tensões com as instituições culturais formais que têm de lidar com a emergência de novas práticas culturais que pipocam pelos espaços da cidade, que circulam pelas redes digitais e se materializam em intervenções culturais e artísticas. Michel de Certeau (1997) há muito perguntara que grupo tem o direito de definir, em lugar dos outros, o que é significativo para eles. Talvez a questão pudesse ser refeita na perspectiva das interações, das negociações e tensões, mas a sensibilidade a essa questão não parece caracterizar as instituições culturais em sua ampla maioria.

O momento atual exige uma compreensão não simplificadora das inúmeras representações, contradições, vozes e silêncios que disputam visibilidade na arena pública, muitas vezes forçando as fronteiras de demarcações preestabelecidas, o uso efetivo da cidade em que a diversidade de vozes constrói coletivamente e conflituosamente as fronteiras, simbólicas ou materiais, que segregam, aproximam, ordenam as relações entre sujeitos e grupos.

Recorrendo novamente a Agamben, sua perspectiva de profanação do sagrado $($ profanar $=$ tirar do templo onde algo foi posto), tema recorrente em sua obra, possibilita a devolução à comunidade humana daquilo que lhe foi subtraído através da sacralização, restituindo ao uso comum. Profanar é assumir a vida como jogo, é aprender a fazer das separações um novo uso, a brincar com elas. Libertação e autolibertação do consagrado, do sagrado. "A passagem do sagrado ao profano pode acontecer também por meio de um uso (ou melhor, de um reuso) totalmente incongruente do sagrado" (AGAMBEN, 2007, p. 66). Especificamente sobre os museus, Agamben é peremptório:

A impossibilidade de usar tem o seu lugar tópico no Museu. A museificação do mundo é atualmente um dado de fato. Uma após outra, progressivamente, as potências espirituais que definiam a vida dos homens a arte, a religião, a filosofia, a ideia de natureza, até mesmo a política - retiraramse, uma a uma, docilmente, para o Museu. Museu não designa, nesse caso, um lugar ou 
um espaço físico determinado, mas a dimensão separada para a qual se transfere o que há um tempo era percebido como verdadeiro e decisivo e agora já não é. $\mathrm{O}$ Museu pode coincidir, nesse sentido, com uma cidade inteira (Évora, Veneza, declaradas por isso mesmo patrimônio da humanidade), com uma região (declarada parque ou oásis natural), e até mesmo com um grupo de indivíduos (enquanto representa uma forma de vida que desapareceu). De forma mais geral, tudo hoje pode tornar-se Museu, na medida em que esse termo indica simplesmente a exposição de uma impossibilidade de usar, de habitar, de fazer experiência (idem, p.73).

Agamben prossegue sua reflexão destacando como o Museu ocupa o lugar reservado anteriormente ao Templo, como lugar de sacrifício no qual os fiéis foram substituídos pelos turistas. Se antes os fiéis e peregrinos participavam do ato sacrificial que restituía as relações entre o humano e o divino, hoje os turistas vivem a angustiante experiência da destruição de qualquer uso possível: reusos e experiências nunca se efetuam, o improfanável se consubstancia. A desativação de velhos usos é a única maneira de profanar, de criar novos usos.

A emergência de processos criativos em espaços distribuídos da cidade, fora das instituições formais está em ebulição, protagonizada sobretudo por jovens e fortemente ancorada nas potencialidades abertas pelas novas tecnologias de informação e comunicação, o que tem modificado as práticas culturais e artísticas, suas estratégias, a forma como os jovens se relacionam com o mundo, a maneira como aprendem, criam, compartilham, se agrupam, colaboram, fazem circular sua criação, se apropriam. Assistimos ao desejo de viver e narrar múltiplas experiências, de extravasar a multiplicidade de vozes não mais contidas nos espaços delimitados, nos canais e instituições tradicionais. Esta nova configuração gera mudanças substantivas nas práticas culturais e artísticas que refletem as mudanças no comportamento da sociedade, e a configuração de novos atores em cena, que ressoam e são eco da esfera política. Com o desejo de participação e assunção da própria voz em várias esferas, e com as potencialidades abertas pelas novas tecnologias de informação e comunicação, as instituições e os canais tradicionais não têm mais o privilégio de definir e dar balizas para a criação e os usos da arte e da cultura.

Assistimos, portanto, a uma transformação profunda dos referenciais, o que exige empenho no enfrentamento da indeterminação, na compreensão da heterogeneidade dos saberes, de práticas e experiências que complexificaram a dinâmica social. Não é mais possível identificar, nos diversos setores da vida pública ou privada, um quadro comum de referências ou valores para os diferentes atores sociais. A localização incerta de muitos processos culturais - produção, circulação, apropriação - vem profanando os lugares legitimados da arte e da cultura e criando novos lugares de experiências culturais e artísticas.

Como as instituições culturais vão lidar com o novo ecossistema cultural é uma perspectiva central a ser problematizada e enfrentada. Existem formas institucionais pertinentes à nova configuração? Quais são elas?

É preciso assumir, como ponto de partida, que a cultura "é o flexível" (DE CERTEAU, 1997), e será sempre um campo de 
incertezas. O desafio é criar espaços que permitam o compartilhamento de incertezas, as interações, a reflexão crítica, que ampliem os limites de manobra no seu interior, permitindo-se maior labilidade, o que resulta no questionamento permanente da própria instituição e da ampliação dos seus limites de ação. Em outras palavras, experimentações institucionais maiores, em que as demarcações não estejam tão estabelecidas, que se abram para novas práticas, como aponta Martin-Barbero ao tratar da renovação do modelo de comunicabilidade a partir da convergência digital “ que privilegia a sinergia entre muitos projetos pequenos acima da complicada estrutura dos grandes e pesados aparatos tanto na tecnologia como na gestão" (2014, p. 22)

A sociedade civil é ator chave na dinâmica contemporânea, e a compreensão dos novos processos nas práticas culturais e artísticas, amplamente ancorados nas tecnologias de informação e comunicação, não pode ser apartada da dinâmica político-social de forma mais ampla. A proximidade e a vida sem mediação são eixos emergentes do protagonismo que vem ganhando corpo e se efetuando nas ruas e nas redes - fluxos e nós, centrados de maneira crescente nas experimentAções, ensaios, tentativas e erros.

Se as instituições culturais desejam ter relevância no futuro e não se manterem como templos de peregrinação sagrada que alimentam a espetacularização da vida, devem se abrir às novas dinâmicas. O alerta feito por Raymond Williams na década de 1950 mantém-se atual: “ acredito que o problema central de nossa sociedade, nos próximos cinquenta anos, é o uso de nossos novos recursos para construir uma cultura em comum" (WILLIAMS, 1958, s.p.); cultura comum não como cultura homogeneizadora, mas como a que se constrói a partir do compartilhamento, das tensões e contradições, das interações e da participação de muitos, da criatividade coletiva, da afirmação de potências, das visibilidades, dos aparecimentos e dos afetos.

\section{Referências}

AGAMBEN, G. Profanações. São Paulo: Boitempo, 2007.

AGAMBEN, G. Infância e História: destruição da experiência e origem da história. Belo Horizonte: Editora UFMG, 2012.

ARENDT, H. "A crise da cultura". IN: Entre o passado e o futuro. São Paulo: Perspectiva, 2013, $7^{\mathrm{a}}$ edição.

CANCLINI, N.G. La sociedad sin relato. Buenos Aires, Katz, 2010.

CANCLINI, N.G. 'La expansión de la cultura: incomodidades para las ciudades y el arte'. In: CANCLINI e VILLORO (org). La creatividad redistribuída. México: Siglo XXI, 2013, p. 13-20.

DE CERTEAU, Michel. A cultura no plural. Campinas: Papirus, 1997.

HALL, S. Da diáspora: identidades e mediações culturais. Belo Horizonte: Editora UFMG, 2009.

HERZOG, W. Conquista de lo inútil: diario de filmación de Fitzcarraldo. Buenos Aires: Entropía, 2013.

MAMMI, L. O que resta: arte e crítica de arte. São Paulo: Companhia das letras, 2012.

MARTÍN-BARBERO, J. "Diversidade em convergência". In: Matrizes. v.8. n.2, p. 15-33, 2015.

TEIXEIRA COELHO, J. Com o cérebro na mão: no século que gosta de si mesmo. São Paulo: Iluminuras, 2015.

WILLIAMS, R. A cultura é de todos. 1958. Tradução Maria Elisa Cevasco. Acessível em https://pt.scribd.com/doc/68474445/ACultura-e-Ordinaria1. Acesso em 25/10/2015. 